\title{
Half a century of continuous oil production by in-situ combustion in Romania - case study Suplacu de Barcau field
}

\author{
Gheorghe Branoiu ${ }^{1,{ }^{*}}$, Florinel Dinu ${ }^{1}$, Maria Stoicescu ${ }^{1}$, Iuliana Ghetiu ${ }^{1}$, and Doru \\ Stoianovici ${ }^{1}$ \\ ${ }^{1}$ Oil-Gas University of Ploiesti, Oil-Gas Engineering Faculty, 39 Bucharest Street, 100680, Ploiesti, \\ Romania
}

\begin{abstract}
Thermal oil recovery is a special technique belonging to Enhanced Oil Recovery (EOR) methods and includes steam flooding, cyclic steam stimulation, and in-situ combustion (fire flooding) applied especially in the heavy oil reservoirs. Starting 1970 in-situ combustion (ISC) process has been successfully applied continuously in the Suplacu de Barcau oil field, currently this one representing the most important reservoir operated by ISC in the world. Suplacu de Barcau field is a shallow clastic Pliocene, heavy oil reservoir, located in the North-Western Romania and geologically belonging to Eastern Pannonian Basin. The ISC process are operated using a linear combustion front propagated downstructure. The maximum oil production was recorded in 1985 when the total air injection rate has reached maximum values. Cyclic steam stimulation has been continuously applied as support for the ISC process and it had a significant contribution in the oil production rates. Nowadays the oil recovery factor it's over 55 percent but significant potential has left. In the paper are presented the important moments in the life-time production of the oil field, such as production history, monitoring of the combustion process, technical challenges and their solving solutions, and scientific achievements revealed by many studies performed on the impact of the ISC process in the oil reservoir.
\end{abstract}

\section{Introduction}

Low recovery factor of the oilfields in the world (averaging 20-30\%) during oil production pushing the oil operators to apply enhanced oil recovery (EOR) techniques in order to improve the ultimate oil recovery factor and accelerating oil production. EOR techniques plays an important role especially in the mature oil fields enhancing the oil production by changing some of the reservoir parameters like crude oil viscosity and interfacial tension and improving oil displacement in the reservoirs. Because there is a growing need for energy and also there is a trend of rising costs of discovery and production of conventional crude oil, it has become necessary to considering the alternative energy sources such as

\footnotetext{
*Corresponding author: gbranoiu@yahoo.com
} 
heavy/extra-heavy oil and natural bitumen. Ratio of conventional and unconventional oil resources in the world are shown in the figure 1, and it can be seen that the heavy and viscous crude oil resources account for 70 percent of the world oil resources. [1-4]

EOR techniques can be divided into thermal oil recovery methods (steam flooding/drive, cyclic steam stimulation, hot water flooding and in-situ combustion) and non-thermal oil recovery methods (alkaline flooding, polymer flooding, and carbon dioxide flooding). Conventionally, thermal EOR methods uses thermal energy to heat heavy oil in order to reduce its viscosity instead the non-thermal EOR suffering in the heavy oil reservoirs due the high mobility contrast between crude oil and injection fluids. Among the EOR techniques, the thermal oil recovery stands out due to its efficiency and to the commercial success. Thermal oil recovery methods are widely applicable worldwide, representing two-thirds of the EOR methods used in the oil recovery (fig. 2). Regarding environmental issues, thermal EOR methods require a special attention from engineers due to the associated $\mathrm{CO}_{2}$ emissions but fortunately these emissions can be collected and injected into reservoirs during applying these techniques to crude oil production. $[1,5]$

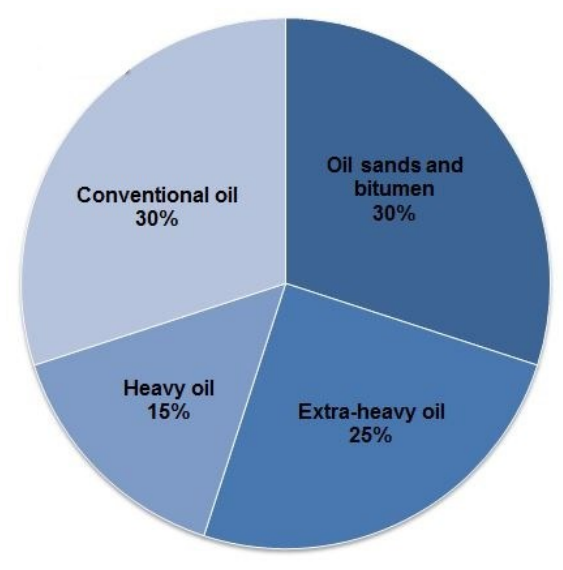

Fig. 1. Ratio of conventional and unconventional oil resources in the world [2]

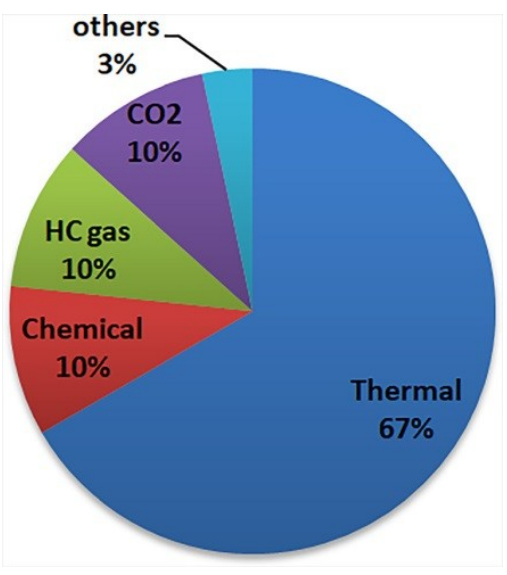

Fig. 2. Ratio of EOR methods used in the oil fields in the world [1]

In the paper we aimed to pointed out the celebration of half a century of successful application of in-situ combustion in the Suplacu de Barcau oil field presenting in a comprehensive manner the history of the exploitation of this famous heavy oil field, reviewing the information on reservoir geology, production history, monitoring of the oil recovery methods applied in the oil reservoir, and technical challenges solved during production life for ensuring the success of the production process. Also a particular attention was paid to the geochemical effects of the EOR thermal methods (in-situ combustion and steam drive) on the reservoir rocks.

\section{Thermal oil recovery}

The most prominent thermal oil recovery methods are steam flooding (steam drive) and insitu combustion (ISC). Thermal oil recovery methods are usually used for so called "heavy oils" meaning oils having less than 22 API deg, but also for extra-heavy oils and bitumen having less than 10 API deg. In the case of heavy oil reservoirs the most thermal recovery method used is steam flooding. The success of the steam flooding process can be severely affected by some parameters such as reservoir depth, reservoir pressure, permeability, porosity and oil saturation. However, the steam flooding is limited to a selective group of 
oil fields. Instead, in-situ combustion is not limited by the depth reservoir. ISC is also applicable in the cases where the heat transfer in the wells can drastically limit the steam injection, like offshore fields and the permafrost regions. ISC is more energy efficient and less polluting than steam flooding, and is not restricted to heavy oil reservoir, the facts already proved by a numerous laboratory studies and field projects operated. However, the ISC process is generally used for the heavy oil reservoirs inappropriate for applying steam flooding. Main disadvantage of ISC is related to poor washing efficiency caused by the mobility contrast between injected air and reservoir fluids. It also requires attention from engineers and is less flexible and error-prone than steam. [1, 6-15]

In-situ combustion (ISC) or fire-flooding is one of the oldest thermal oil recovery designed and patented in 1920 in U.S. [8, 10]. ISC has proved as an efficient thermal method for heavy oil recovery which use the heat generated in the reservoir by burning a part of the heavy oil in order to decrease the crude oil viscosity improving the oil mobility and hence oil production and recovery. Combustion gases drive and recondensed water drive are the main mechanisms by which the crude oil is driven toward the production wells. During ISC, in the oil reservoir takes place many physico-chemical transformations including thermal cracking and distillation of crude oil, modifying physical parameters of the reservoir and chemico-mineralogical transformations of the porous media. Thermal cracking of the crude oil determine the formation of a solid fuel called "coke". The coke burning is supported by injecting air or an oxygen rich gas into the reservoir. [1, 6-12]

According to the direction of injected air and combustion front there are two types of ISC: "forward combustion" if the air and combustion front are moving in the same direction, and "reverse combustion" if the injected air and the combustion front are countercurrent. Forward combustion can be divided into "dry forward combustion" (in the oil reservoir is injected only air to support the combustion) and "wet forward combustion" (in the oil reservoirs, air and water are co-injected into the formation through the injection well). Currently in the world only forward in-situ combustion (fig. 3) is operated in the oil industry. ISC is a complex recovery process which include steam distillation, steam displacement, carbon dioxide flooding, hydrocarbon miscible flooding, immiscible gas displacement, and hot and cold water flooding. Clastic sedimentary rocks (like sands and sandstones) with high porosity are the most suitable for ISC, but lately ISC was intensively applied also in the carbonate rocks. $[1,6-8,16]$

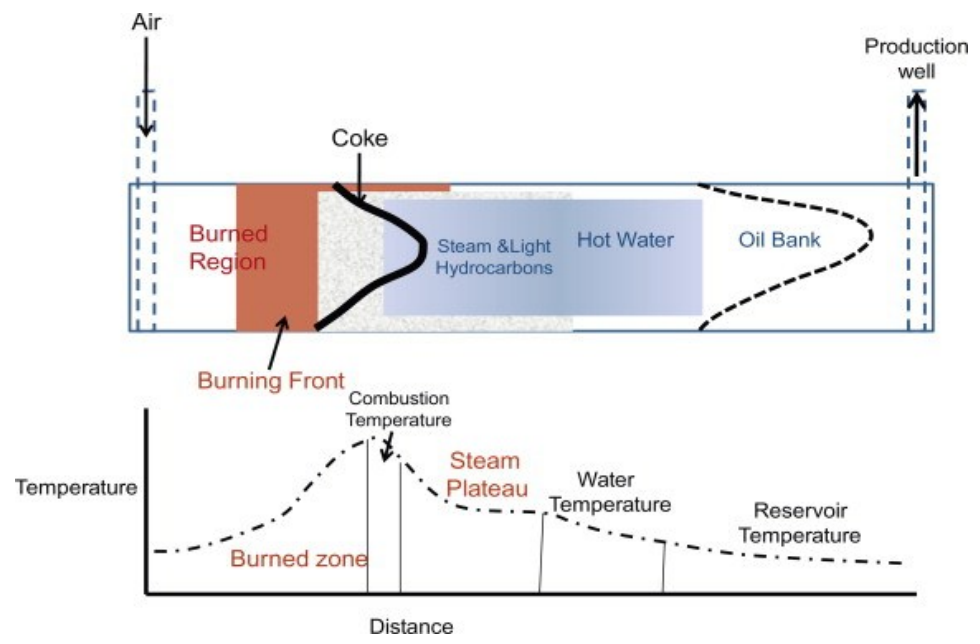

Fig. 3. Illustration of a forward ISC process [16] 
ISC process can be applied in different configurations/systems. Thus, starting 1950 were tried both wells panels/patterns (adjacent or isolated patterns) and peripheral line drive (i.e. combustion front) located up-structure or down-structure. The most ISC projects have used adjacent patterns and peripheral line drive configuration. [8, 10] In the 1990s engineers have searched new ways to improve ISC process. Thus were developed new methods for applying ISC in combination with horizontal production wells such as: Toe-toHeel Air Injection (THAI) and its catalytic variation, Catalytic Upgrading Process In-situ (CAPRI); top-down in-situ combustion (TD-ISC); basal in-situ combustion (BISC); steam assisted gravity drainage (SAGD) and its variations, Vapour-Assisted Petroleum Extraction (VAPEX) and Solvent-Assisted Steam-Assisted Gravity Drainage (SA-SAGD).

First successful application of an ISC process was in the West Newport project (US, California) with a series of irregular inverted 5-spot patterns. [8]. In the past seventy years have been in operation approximately 270 ISC field pilots [7, 15], and in the 1970-1980 period were recorded 19 commercial ISC projects. $[8,10]$ Currently, five active successful commercial ISC projects include the Suplacu de Barcau field in Romania, the Balol and Santhal fields in India, Bellevue field in US and the Liaohe field in China. [10, 14, 15]

\section{Suplacu de Barcau oil field: case study of successful ISC operations}

Suplacu de Barcau field is a brown oil field but it is still one of the most important oil fields in Romania. The oil field has been operated since 1960 and currently is the largest oil field operated by ISC in the world. In this oil field significant potential left from its $130 \mathrm{MMbbls}$ oil reserves (2P) and currently accounts around 10 percent of the Romanian daily oil production with an oil production rate of 8,500 bbls/day and an oil recovery factor over 50 percent.

\subsection{Reservoir geology}

Suplacu de Barcau oil field is situated in the Northwestern Romania, $70 \mathrm{~km}$ East from the Oradea city. Geologically the oil field belongs at regional scale to Eastern Pannonian Basin and locally to Abramut sub-basin (fig. 4). In terms of the petroleum geology Suplacu de Barcau reservoir belongs to the Miocene-Thermogenic petroleum system of the Pannonian Basin. [17] Heavy oil is reservoired in shallow deposits and trapped on the eastern flank of a foreland basin (i.e. Pannonian Basin) in the similar geological setting with the most of the heavy/extraheavy oil accumulations. As it is generally known the heavy oils comes from conventional oils that migrates upward to shallower traps frequent with lack effective sealing caprocks, and creating adequate conditions to severe degradations of the conventional oils to heavy/extraheavy oils.

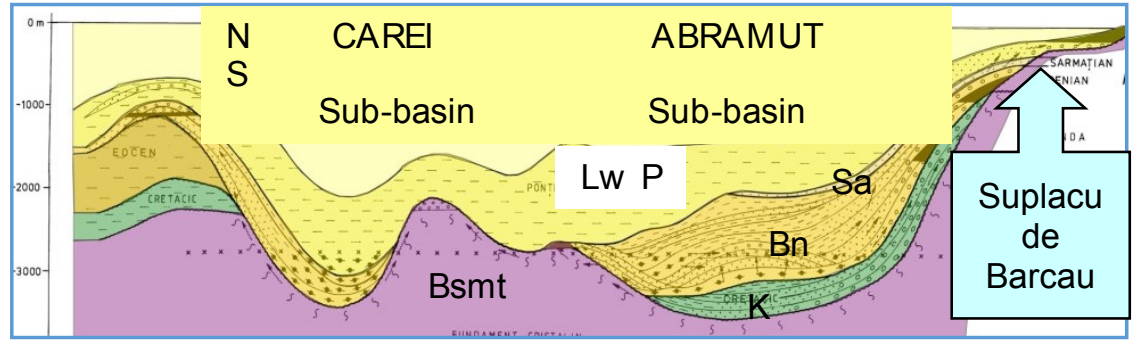

Fig. 4. Regional cross section in the Eastern Pannonian Basin (Bsmt - basement; $\mathrm{K}$ - Cretaceous; $\mathrm{Bn}$ - Badenian; Sa - Sarmatian; Lw P - Lower Pannonian = Pliocene) [18] 
Suplacu de Barcau field is heavy oil (asphalt-base-oil type), shallow Pliocene (Pannonian) clastic reservoir, and it was formed by covering the crystalline basement with a Neogene sedimentary suite. The structure is a slightly-folded monocline (fig. 5) of approximately $15 \mathrm{~km}$ length, East-West oriented, with a fault-dependent closure to the south. The reservoir it is bordered to the North and West by a weak aquifer. The reservoir depth and thickness, as well as the facies of the reservoir rocks vary both vertically and laterally. Geological characteristics of the reservoir rocks are as follows: littoral-deltaic facies, unconsolidated/weak consolidated quartzite sands, fine to coarse grained, variable sorting, generally poorly sorted. As intercalations were encountered clayey sands, polymictic sands, marlstones, greywackes, subgreywackes and microconglomerates. $[4,10-$ $12,18-20]$ More details on the reservoir parameters are presented in the table 1.

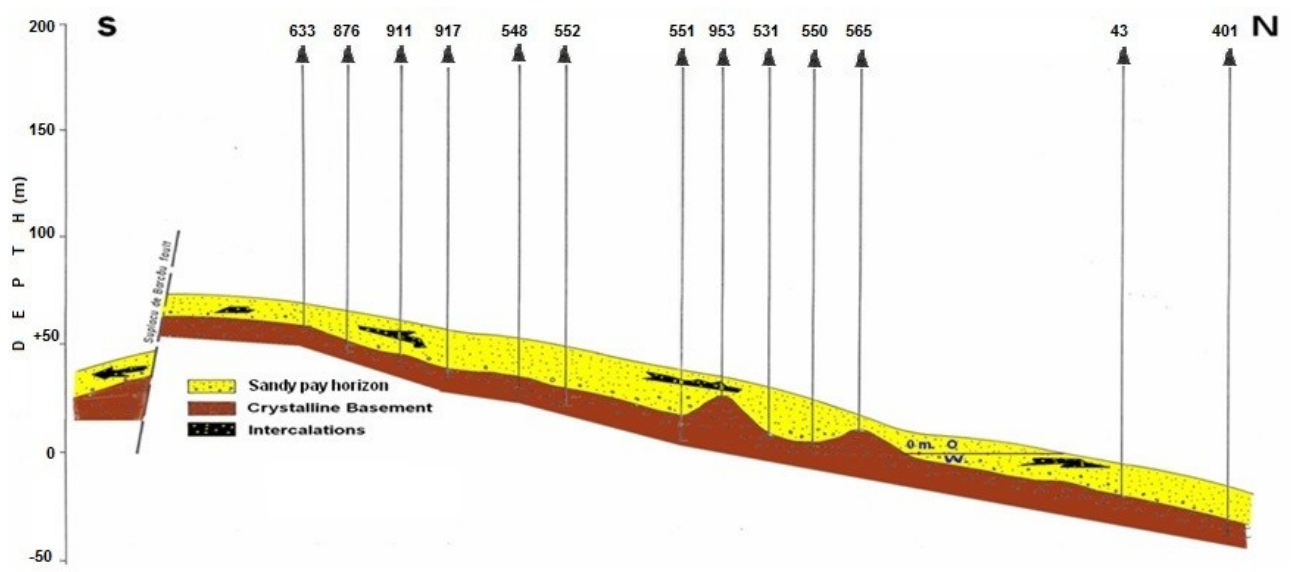

Fig. 5. Geological cross-section in the Suplacu oilfield [18]

Table 1. Main reservoir parameters of the Suplacu de Barcau field [10, 18-22]

\begin{tabular}{|l|l|}
\hline Parameter & Value \\
\hline Surface [ha] & 1700 \\
\hline Depth [m] & $35-220$ \\
\hline Total sand [m] & $6-35$ \\
\hline Net pay thickness [m] & $4-24$ \\
\hline Dip [degree] & $5-8$ \\
\hline Initial reservoir pressure [bar] & $4-22$ \\
\hline Reservoir pressure at start of ISC [bar] & $5-6$ \\
\hline Initial reservoir temperature [Celsius degree] & 17 \\
\hline Porosity [\%] & 32 \\
\hline Initial oil saturation [\%] & $79-85$ \\
\hline Irreducible water saturation [\%] & 15 \\
\hline Absolute permeability [mD] & $2000-2300$ \\
\hline Oil dynamic viscosity [cP] & $1800-2500$ \\
\hline Oil density [kg/m ${ }^{3}$ ] & 960 \\
\hline Oil gravity [API degree] & 16 \\
\hline OOIP [MMbbls] & 310 \\
\hline 2P oil reserves [MMbbls] & 130 \\
\hline
\end{tabular}




\subsection{Production history}

Suplacu de Barcau oil field was discovered in the 1956-1960 period and has entered in production in 1960. At starting production of the reservoir (1960) the main production mechanism was solution gas drive with modest oil rates $\left(2\right.$ to $5 \mathrm{~m}^{3} /$ day/well decreasing to 0.3 to $1 \mathrm{~m}^{3} /$ day/well). At that time was predicted an ultimate oil recovery of $9 \%$ (requiring more than 80 years) in the case of application of solution gas drive as production mechanism. Thus, in order to increase oil recovery were considered thermal oil recovery methods. During 1963 to 1970 in the upper part of the structure were tested concomitantly two thermal recovery methods, ISC and steam drive (fig. 6), in order to make an efficient selection of the production method of the reservoir. [10, 18-22]

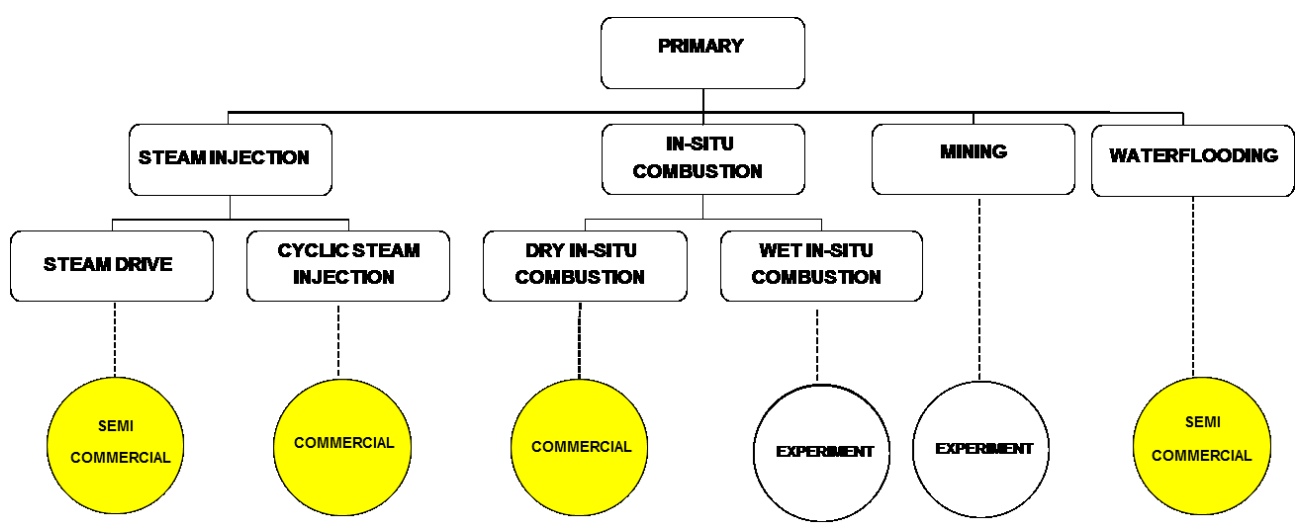

Fig. 6. Oil recovery methods used/tested during production life of the Suplacu oilfield [18]

Initially, ISC and steam drive were tested in two five-spot panels $(0.50$ ha area) with a central injection well (fig. 7) located in the upper part of the structure, further expanded in nine-spot panels ( 2 ha area). In a second stage, around original panels was started, in six adjacent panels of 2-4 ha area, for both ISC and steam drive a semi-commercial recovery of the reservoir. During 1965-1970, in the middle and in the lowest part of the structure, was tested other two experimental ISC panels. The operation of the last two panels revealed the difficulty in terms of the controlling and efficiency of the ISC process compared to the location of the panels in the upper part of the structure. [10, 18-22]

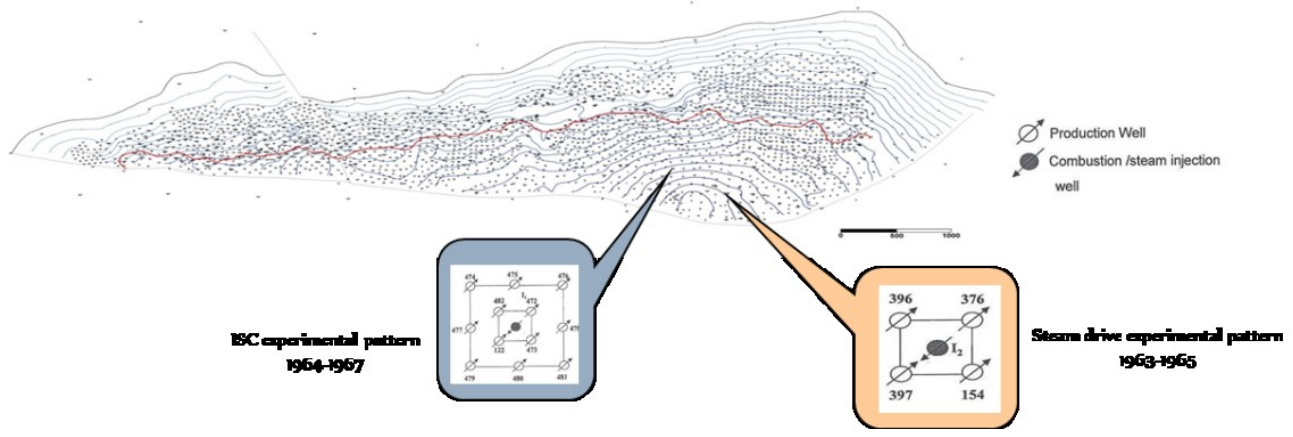

Fig. 7. First field pilot tests in the Suplacu oilfield [18] 
Field pilot tests performed during 1964 to 1970 were proven both ISC and steam drive to work at an industrial scale. Better performance of the ISC process led to the decision taken in 1970 to use ISC for commercial operation of the field. Other decisions taken by the engineers were applying cyclic steam stimulation (CSS) to support the ISC process and converting the experimental ISC patterns into ISC line drive operation. Theoretical and laboratory studies and field pilot tests have supported the idea that the best option for ISC field operation is producing the reservoir down the structure (fig. 8), from the South to the North. [10, 18-22]

Starting 1979, the ISC process has been driven downstructure as linear ISC front (fig. 7, 8). The distance between air injection wells (fig. 8) was 50-75 m between two neighboring wells, and the row of air injection wells oriented approximately East-West had a length of over $10 \mathrm{~km}$. Later, in 1986, the ISC process was extended in the Western part of the field. In 1983 was opened a second linear ISC front, parallel to the main one but located downstructure. The second ISC front was abandoned in 1996 due to its poor performance. In 1998, as a result of reducing the air injection rates and the CCS steam volume was registered a decline of oil production. Starting 2007 was tested water injection behind ISC front. A schematic application of the water flooding in the burned zones with probable reserves resulted applying the process is shown in figure 9. [10, 18-22]

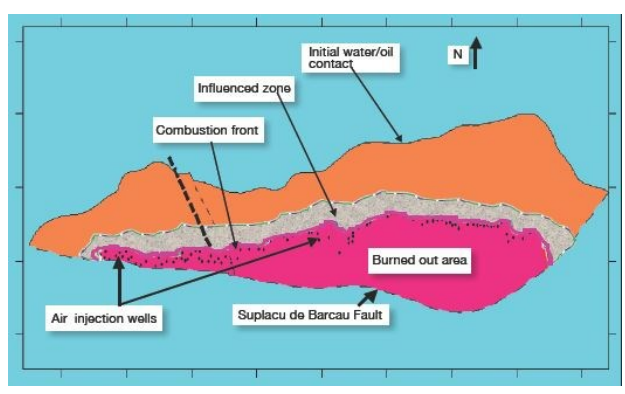

Fig. 8. Status (July 2004) of the forward ISC in the Suplacu de Barcau field [10]

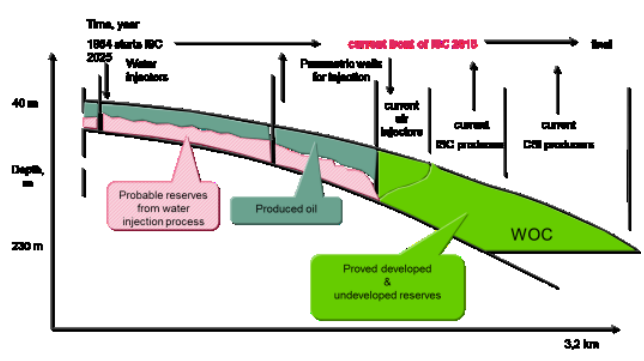

Fig. 9. Application of the water flooding in the burned zones [18]

Analyzing the performance of the commercial ISC process (fig. 10) it can be observed that maximum oil production was recorded in 1985-1991 period, corresponding to a maximum value of the total air injection rate. The general trend of air-oil ratio (AOR) is an increasing one, and currently it is in the range of 2,600-3,200 sm $3 / \mathrm{m}^{3}$. Applying of the CSS as support recovery methods for the ISC process (fig. 11) it had a significant contribution (around 20\%) in terms of the production performance. Considering the real performance of the wells and also the low volumetric sweep due to the channeling phenomena an ultimate oil recovery factor close to 60 percent was predicted. [10, 18-22] More details on the ISC parameters are presented in the table 2 . 


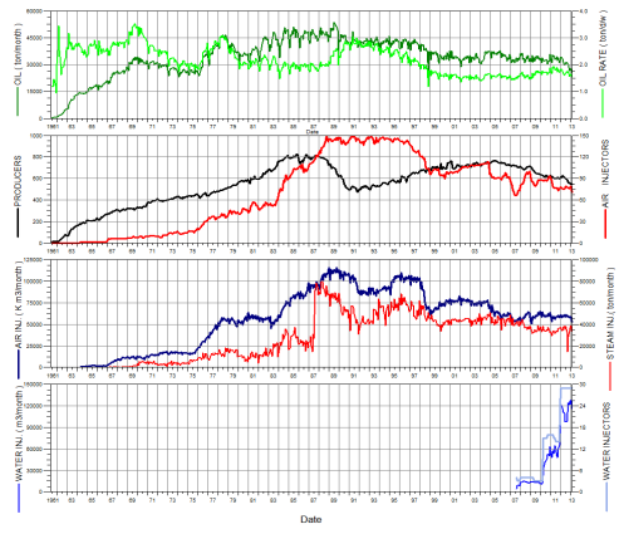

Fig. 10. Performance of the commercial ISC process $[10,18]$

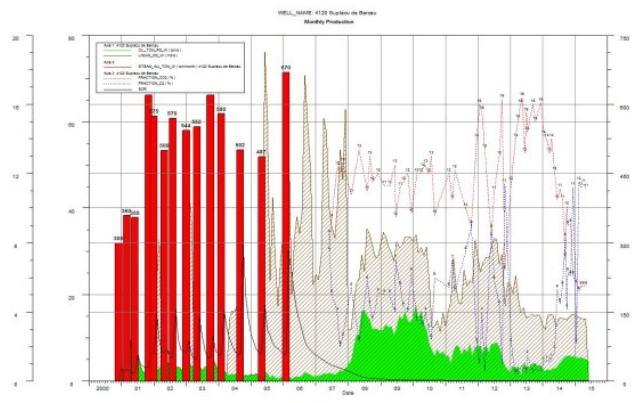

Fig. 11. CSS + ISC well production profile [18]

Table 2. ISC process status 2015 ([18] compiled with [10, 19])

\begin{tabular}{|l|l|}
\hline Start commercial operations & 1971 \\
\hline Total wells drilled & 2913 \\
\hline Wells in production & 480 \\
\hline Oil rate & $1.79 \mathrm{t} / \mathrm{day} /$ well \\
\hline Cyclic steam injection wells & $19-23$ wells / day \\
\hline Air injection wells & 68 wells $/$ day \\
\hline Oil rate (field) & $850 \mathrm{t} /$ day \\
\hline Air injection rate & $1790 \times 10^{3} \mathrm{Stm}^{3} /$ day \\
\hline Steam injection rate & $1150 \mathrm{t} / \mathrm{day}^{3}$ \\
\hline Air/oil ratio & $3218 \mathrm{Stm}^{3} / \mathrm{m}^{3}$ \\
\hline Injection pressure & $10-14 \mathrm{bar}$ \\
\hline Oxygen utilization & $95 \%$ \\
\hline Current water cut & $82 \%$ \\
\hline Steam/oil ratio & $2.64-3.32 \mathrm{t}$ steam/t oil \\
\hline Recovery factor & $50.8 \%$ \\
\hline
\end{tabular}

Some of the main time frames in the production life of the Suplacu de Barcau field are as follows:

- 1961 - start of production in solution gas drive mechanism

- 1963 - 1965 Steam Drive Pilot pattern

- 1964 - 1970 ISC Pilot pattern

- $\quad$ 1970-1971 - starting forward (dry) ISC process

- 1975 - ISC operated in linear front combustion

- 1975 - increasing stimulation with steam (CSS)

- 1976 - increasing air injection capacity

- 1979 - is tested wet ISC

- $\quad 1983$ - the second ISC front

- 1985-1991 - maximum oil production

- 1989-1991 - maximum level of total air injection

- $\quad 1996$ - stop of the second ISC front

- 1998 - reducing of the air injection rates and the CSS steam volume

- 2005 - ISC continued in peripheral line drive

- 2007 - water injection behind ISC front (test) 
- 2009 - development of water injection

- 2010 - first three horizontal wells

- 2013 - Steam drive test started

- 2015 - around 2900 wells spudded

\subsection{Monitoring of the ISC process}

Monitoring of the ISC process is a complex operation that include:

- ignition in the wells,

- pressure and temperature measurements in the wells during ignition,

- measure volume and content of exhausted produced gas,

- monitoring of air injection parameters.

In the ISC process a key element is represented by well ignition. The ignition supposes assuring the saturation with oxygen of the ignition zone and generating a temperature higher than $400^{\circ} \mathrm{C}$. When the ignition is finalized the well turns into a combustion well. Air injection in this well creates and keeps the front burning. As well ignition methods were used electrical methods and with combustible gases methods. During ignition were performed pressure and temperature measurement in the wells. [18-22]

Measure volume and content of exhausted produced gas pursued following operations:

- gas sampling (500 analyses/month or at least $1 /$ well/month),

- gas flow rate measurement (200/month),

- pressure measurements and temperature profiles in wells.

Monitoring of air injection parameters supposes a permanent adjusting of air injection rates and recording of the parameters in databases in order to use them for periodical analyses of the panels behaviour. In the affected areas, the combustion gas component ratio is changing.

This could indicate that combustion reactions are adequate or needs to be re-ignite or to change the injection rate (fig. 12). In the Suplacu de Barcau oil field the $\mathrm{H} / \mathrm{C}$ ratio in the range 1-2 show good combustion parameters, while $\mathrm{H} / \mathrm{C}$ ratio higher than 2.5 indicate low temperature oxidation which is not proper for combustion (the oil gets mostly heavier). Cracking at high temperatures will generate unsaturated hydrocarbons. Also low values of $\mathrm{CO}_{2}$ indicate low temperature oxidation (less than $250^{\circ} \mathrm{C}$ ) and/or air channelling. [18-22]

\subsection{Monitoring of the CSS process}

Monitoring of the CSS process (fig. 13) is composed by two stages: (1) preparing steam injection and (2) operations during steam injection.

Preparing steam injection include well preparation for steam injection and surface facility preparation of well head \& pipes tightness, pipe's thermo isolation and all measurement devices.

Operations during steam injection include:

- Continuous measurement of parameters (injection rate, temperature, pressure) and

- Recording parameters in databases in order to use for periodical analyses of the wells behaviour after CSS as: flow rate; watercut changing; temperature changing; steam-oil ratio (SOR) evolution; interferences between wells 


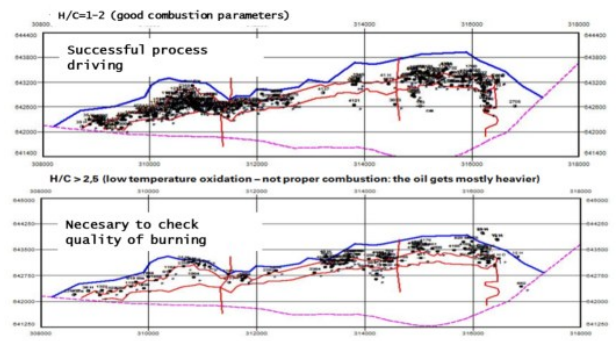

Fig. 12. Combustion gas components monitoring [18]

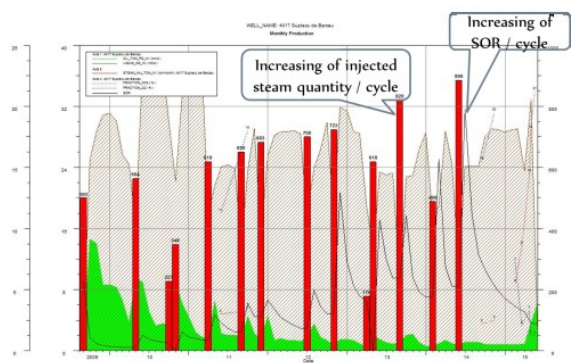

Fig. 13. CSS well production profile [18]

\subsection{Technical challenges}

In the production life of an oilfield operated by ISC there are many technical, operational and managerial challenges to solve for ensuring the success of the ISC process. Some of these technical and operational challenges are represented by: optimizing air rate; maximizing oil rate; reducing operating costs; assessing steam drive potential; gravity segregation; controlling air channelling; controlling of air/oil ratio (AOR); low sweep of reservoir; fluids processing; managing production and surface facilities; monitoring of the ISC and CSS processes; monitoring of the combustion process; solving of the environmental issues caused by $\mathrm{H}_{2} \mathrm{~S}, \mathrm{SO}_{2}, \mathrm{CO}_{2}$ and hydrocarbon gases. [18-22]

Starting 1972 a Combustion Laboratory was designed in the ICPT Campina in collaboration with the Institute Francaise du Petrole. The combustion laboratory was equipped with: temperature ramped oxidation cell, Conradson coke device, electric oven; gas analysers, combustion tube. Several studies performed in the combustion laboratory in the ICPT Campina were as follows: formation and burning of the coke in the ISC process; application of combustion with air enriched in oxygen; application of wet combustion; oxidation process at lower temperatures and their influence on the ISC process; application of ISC in combination with horizontal wells; changes determined by ISC on the physicochemical properties of the crude oil; monitoring of the ISC process; analysis of the produced fluids. [18-22]

It is important to mention that ISC commercial process in the Suplacu de Barcau field used mainly Romanian equipment and installations.

\subsection{Scientific achievements}

Scientific research carried out over time by G. Aldea, A. Carcoana, V. Machedon, M. Zamfir, A. Turta, A. Condrachi, and others, on the design, performance, and the impact of the ISC process on the Suplacu de Barcau reservoir have international recognition and are not detailed in this paper. Instead we will make known research and scientific achievements and especially doctoral thesis equally important in terms of the impact of ISC in the Suplacu de Barcau field. Thus the mineral transformations under the influence of multiple factors acting in the ISC process (temperature, pressure, volatile substances, various liquid solutions, organic substances) were accidentally approached by studies on the physicochemistry of the oil reservoirs and only in close connection with coke formation considered as fuel in the combustion processes. Older or more recent studies on the permeable-porous media affected by the combustion front show that the main transformations of minerals that occur in oil reservoirs operated by ISC are: dissolution, recrystallization, loss of crystallization water, polymorphic transformations, thermal decomposition. 
The research conducted by I.D. Parcalabescu et al. (1980, 1986, 1988, 1989) [23-27] on the influence of the ISC process on the rock-fluid system focused on X-rays diffraction and chemical-spectral analyzes led to interesting conclusions as follows: (1) the critical diameter of the coke is $5 \AA$ on the X-ray diffractograms, and the coke molecule is strongly polar; (2) - in the rock pores there is no free coke macroscopically visible, but on the X-ray diffractograms and in the chemical-spectral analyzes coke was highlighted in the crystalline network of montmorillonite which it swelling at 20-21 ; (3) during combustion organometallic structures are formed (oxalates, formates, acetates, phthalates, etc.) whose determination gives indications on the physico-chemical conditions of the ISC; (4) the crude oil influenced by ISC changes its chemical and structural composition; (5) at temperatures higher than $450^{\circ} \mathrm{C}$ have encountered the rupture of the naphthenic and aromatic cycles of crude oil and their transformation into linear chains by dehydrogenation; (6) the acidity index of crude oil influenced by ISC increases due to the dehydrogenation of naphthenic and petroleum acids from crude oil.

Other distinguished researcher was T. Cristescu (1997) [28] who carried out a series of experimental research to highlight the physical and chemical transformations of the rockfluid system in the conditions of an oil reservoir operated by ISC using rock samples collected from Videle and Suplacu de Barcau oil fields. The laboratory experiments, supplemented by microstructural analyzes (X-rays diffraction, chemico-spectral analyses, chemical analyses) on the rock samples used in the Videle and Suplacu de Barcau reservoirs, led the author to theoretical and practical conclusions as follows: (1) the physical and chemical transformations that take place in an oil field operated by ISC are influenced primarily by temperature and running time, and lead to changes in the chemical and mineralogical composition of the solid rock media, the thermal conductivity of the solid rock media and of the liquid media, and of the saturation in fluids; (2) with the increase of the temperature of the ISC process, chemical transformations of the solid rock media take place, which lead to the modifications of the chemical-mineralogical composition, and the permeability and porosity of the rocks; (3) the presence of clay minerals justifies the hypothesis that thermocatalytic reactions take place in ISC, natural clays being active catalysts for catalytic cracking; (4) in certain conditions, there is the possibility of chemical reactions between metals and derivatives of organic substances, as a result of which complex derivatives are obtained, such as organometallic compounds.

In other doctoral thesis N. Trasca-Chirita (1998) [29] undertook research on improving the design, monitoring and driving of the oil reservoirs operated by ISC showing the followings: (1) the nature and amplitude of the reactions that take place in an oil field operated by ISC depend largely on the temperature of the combustion front and on the possible presence of reaction catalysts; (2) the most frequent reactions in the solid media of the reservoirs operated by ISC are the thermal decomposition reactions that take place in most minerals, the most influenced being the clay minerals due to their high ionic exchange capacity; (3) clay minerals have a high affinity for water, unfavorable case due to reduced permeability by swelling and migration of clay particles; (4) clay minerals have a high affinity for the polar components of crude oil (heavier fractions), an aspect that facilitate the deposition of coke in the reservoir; (5) during an ISC process, silicates and alumosilicates can be dissolved in the water formed depending on its temperature, $\mathrm{pH}$ (the most favorable is a $\mathrm{pH}$ of 10-11), and salinity, the resulting precipitates leading to the reduction of the permeability of the reservoir rocks.

Remarkable results were obtained also by V.E. Vasiliu (1998) [30] in his doctoral thesis in which carried out research on the minerals from the rocks of the Suplacu de Barcau reservoir in order to highlighting their modifications as a result of the application of the ISC process. For a good understanding of the complicated mineralogical processes that take place during ISC, V.E. Vasiliu uses an experiment that consisted of burning of some rock 
samples in a combustion cell at different temperatures (e.g. $300^{\circ} \mathrm{C}, 500^{\circ} \mathrm{C}, 800^{\circ} \mathrm{C}$ ) and performing a comparative study between the control sample unaffected by combustion (calcareous sandstone) and the samples burned at high temperatures highlighting a whole series of mineralogical transformations. The author also made investigations on rock samples collected from the burned area of the oil field. Processes of recrystallization of the micritic mass, of the peloids, the appearance of a fissure system, processes of redeposition, and processes of calcite crystals growth were highlighted. Electron microscopy reveals well-developed crystalline individuals for high temperature samples and recrystallizationdissolution processes, and X-ray diffraction, in addition to characterizing mineralogical changes, proves forming of new mineralogical species during ISC, such as calcium hydride, calcium acetylide, wollastonite and wairakite.

Finally G. Branoiu (2007) in his doctoral thesis [11], and subsequently [4, 12], performed a complex geological study consisting of mineralogical investigations by optical microscopy, X-rays diffraction and thermal analysis (thermogravimetric and thermodifferential analysis) on the rock samples collected from the burned area of the Suplacu de Barcau oil field. In the mentioned research it is shown that the reservoir rocks of the Suplacu de Barcau oil field have suffered a variable thermal regime with temperatures in the range $150-500^{\circ} \mathrm{C}$, which is proved by the mineralogical transformations and the exothermic/endothermic transformations observed in the rock samples studied.

Investigations by X-rays diffraction and optical microscopy performed by G. Branoiu $[4,11,12]$ showed significant mineralogical transformations consisting in decreasing of the clay minerals content, formation of new minerals (calcium silicates hydrated and tobermorite minerals) and also grain size changes in the burned samples collected in the wells spudded in the burned area of the reservoir (K8, K20, K30, and K40). Decreasing of the clay minerals content and grain size changes have influence on the physical rock parameters modifying the porosity and the permeability and subsequently influencing the oil production rate in the reservoir. Forming of the new minerals (calcium silicates hydrated and tobermorite) is controlled by several factors associated with hydrothermal-type conditions encountered in the oil reservoirs operated by ISC (similar with the conditions from Portland-type cements) such as: (1) the existence of raw mineral sources; (2) increasing of the chemical reaction rates; (3) the sweeping of the porous media by hot fluids facilitating the dissolution and the transport in solution of the raw mineral sources; and (4) high temperatures/high pressures conditions.

\section{Conclusions}

Suplacu de Barcau oil field is one of the biggest oil fields in Romania and probably the largest oil field operated by ISC in the world. During the ISC process the reservoir rocks of this heavy oil field have suffered a variable thermal regime with temperatures in the range $150-500^{\circ} \mathrm{C}$, which is proved in the several previous studies on the solid-fluid system of the reservoir.

There is a significant potential for the association of ISC with other recovery methods: steam drive injection, cyclic steam stimulation, water injection behind the font, air rate optimization. Thus, the support of the cyclic steam stimulation (CSS) in operating the ISC process it had a significant contribution (around 20\%) in the ultimate oil recovery factor. ISC process in Suplacu de Barcau oil field benefit of the gravity advantage due to driving the ISC front downstructure, but low volumetric sweep due to the channeling phenomena led to the prediction of an ultimate oil recovery factor close to 60 percent.

In the production life of an oil field operated by ISC there are many technical, operational and managerial challenges to solve for ensuring the success of the ISC process. Some of the technical challenges are represented by: optimizing air rate; maximizing oil 
rate; reducing operating costs; fluids processing; monitoring the combustion process; solving of the pollution problems caused by $\mathrm{H}_{2} \mathrm{~S}, \mathrm{SO}_{2}, \mathrm{CO}_{2}$ and hydrocarbon gases.

The studies performed on the impact of the ISC process in the Suplacu de Barcau reservoir have revealed a series of scientific achievements: evidence of forming of organometallic compounds; facilitating the deposition of coke in the reservoir by clay minerals due to their high affinity for the polar components of crude oil (heavier fractions); evidence of gradual stages of transformation (burning) of the organic substance; the presence of secondary pellicles of the hydrocarbon movement on the walls of the pores; evidence of forming of the calcium silicates hydrated (C-S-H) of tobermorite-type; estimation of the combustion temperature profile by mineralogical transformations and modeling of the reservoir thermal regime.

\section{References}

1. E.M.A. Mokheimer, M. Hamdy, Z. Abubakar, M.R. Shakeel, M.A. Habib, M. Mahmoud, J. Energy Resour. Technol. March 2019; 141, 1-18 (2019)

2. H. Alboudwarej, et al., Oilfield Review 2006 (Schlumberger, 2006)

3. C. Curtis, et al., Oilfield Review 2002 (Schlumberger 2002)

4. G. Branoiu, T. Cristescu, I. Nistor, Rev.Chim.(Bucharest), 69, 10 (2018)

5. A.R. Kovscek, J. Pet. Sci. Eng., 98-99 (2012)

6. J. Burger, P. Sorieau, M. Combarnous, Thermal methods of oil recovery (Editions Technip, Paris, 1985)

7. M. Prats, Thermal Recovery (Second Printing SPE, Henry L. Doherty Memorial Fund of AIME, New York, Dallas, 1986)

8. P. Sarathi, In-Situ Combustion Handbook Principles and Practices (National Petroleum Technology Office, Tulsa, OK, 1999)

9. L.M. Castanier, W.E. Brigham, J. Pet. Sci. Eng., 39, 1-2 (2003)

10. A.T. Turta, S.K. Chattopadhyay, R.N. Bhattacharya, A. Condrachi, W. Hanson, J. Can. Pet. Tech., 46, 11 (2007)

11. G. Branoiu, Doctoral Thesis (Universitatea Petrol-Gaze din Ploiesti, 2007)

12. G. Branoiu, T. Cristescu, Rev. Chim. (Bucharest), 68, 2 (2017)

13. H.S. Dayal, B.V. Bhushan, S. Mitra, S.K. Sinha, S. Sur, SPE paper 126241 (2010)

14. K. Aounallah, SPE paper 199775-STU (2019)

15. W. Zheng, X. Tan, T. Wang, Y. Bai, Pet. Sci. Tech., 38, 22 (2020)

16. T. Ahmed, D.N. Meehan, Advanced Reservoir Management and Engineering (Second Edition, Gulf Professional Publishing, 2012)

17. G. Branoiu, General framework of exploration-production activities in Romania (Editura Universitatii Petrol-Gaze din Ploiesti, 2019)

18. *** OMV-Petrom company, Asset 1 report/presentation (Suplacu de Barcau, 2015)

19. A. Panait-Patica, D. Serban, N. Ilie, SPE paper 100346 (2006)

20. J. Ruiz, P. Naccache, A. Priestley, G. Glatz, V. Crecana, SPE paper 165490 (2013)

21. G. Aldea, A. Turta, M. Zamfir, 4th UNITAR/UNDP, The in-situ combustion industrial exploitation of Suplacu de Barcau field, Romania (Edmonton, Canada, 1988)

22. V. Machedon, DOE/NIPER Symposium, Romania - 30 Years of experience in in-situ combustion (Tulsa, Oklahoma, 1994)

23. I.D. Parcalabescu, Bul. I.P.G. Ploiesti, 31 (1980)

24. I.D. Parcalabescu, I. Nistor, Mine, Petrol si Gaze, 37, 11 (1986)

25. I.D. Parcalabescu, I. Nistor, Mine, Petrol si Gaze, 37, 12 (1986)

26. I.D. Parcalabescu, I. Nistor, Mine, Petrol si Gaze, 39, 7 (1988)

27. I.D. Parcalabescu, D. Besnea, Mine, Petrol si Gaze, 40, 4 (1989) 
28. T. Cristescu, Doctoral thesis (Universitatea Petrol-Gaze din Ploiesti, Facultatea Ingineria Petrolului si Gazelor, 1997)

29. N. Trasca-Chirita, Doctoral thesis (Universitatea Petrol-Gaze din Ploiesti, Facultatea Ingineria Petrolului si Gazelor, 1998)

30. V.E. Vasiliu, Doctoral thesis (Universitatea Petrol-Gaze din Ploiesti, Facultatea Ingineria Petrolului si Gazelor, 1998) 